\title{
Mapping tsunami impacts on land cover and related ecosystem service supply in Phang Nga, Thailand
}

\author{
G. Kaiser ${ }^{1}$, B. Burkhard ${ }^{2}$, H. Römer ${ }^{3}$, S. Sangkaew ${ }^{4}$, R. Graterol ${ }^{2}$, T. Haitook ${ }^{5}$, H. Sterr ${ }^{6}$, and D. Sakuna-Schwartz ${ }^{7,8}$ \\ ${ }^{1}$ Norwegian Geotechnical Institute, Oslo, Norway \\ ${ }^{2}$ Institute for Natural Resource Conservation, Christian-Albrechts-Universität zu Kiel, Kiel, Germany \\ ${ }^{3}$ German Remote Sensing Data Center (DFD), German Aerospace Center (DLR), Oberpfaffenhofen, Germany \\ ${ }^{4}$ Asian Institute of Technology, Bangkok, Thailand \\ ${ }^{5}$ Department of Animal Science, Faculty of Agriculture, University of Khon Kaen, Khon Kaen, Thailand \\ ${ }^{6}$ Institute of Geography, Christian-Albrechts-Universität zu Kiel, Kiel, Germany \\ ${ }^{7}$ Institute of Geosciences Sedimentology, Coastal and Continental Shelf Research, Christian-Albrechts-Universität zu Kiel, \\ Kiel, Germany \\ ${ }^{8}$ Oceanography and Environment Unit, Phuket Marine Biological Center, Phuket, Thailand
}

Correspondence to: G. Kaiser (gka@ngi.no)

Received: 30 April 2012 - Published in Nat. Hazards Earth Syst. Sci. Discuss.: -

Revised: 5 July 2013 - Accepted: 16 July 2013 - Published: 5 December 2013

\begin{abstract}
The 2004 Indian Ocean tsunami caused damages to coastal ecosystems and thus affected the livelihoods of the coastal communities who depend on services provided by these ecosystems. The paper presents a case study on evaluating and mapping the spatial and temporal impacts of the tsunami on land use and land cover (LULC) and related ecosystem service supply in the Phang Nga province, Thailand. The method includes local stakeholder interviews, field investigations, remote-sensing techniques, and GIS. Results provide an ecosystem services matrix with capacity scores for 18 LULC classes and 17 ecosystem functions and services as well as pre-/post-tsunami and recovery maps indicating changes in the ecosystem service supply capacities in the study area. Local stakeholder interviews revealed that mangroves, casuarina forest, mixed beach forest, coral reefs, tidal inlets, as well as wetlands (peat swamp forest) have the highest capacity to supply ecosystem services, while e.g. plantations have a lower capacity. The remote-sensing based damage and recovery analysis showed a loss of the ecosystem service supply capacities in almost all LULC classes for most of the services due to the tsunami. A fast recovery of LULC and related ecosystem service supply capacities within one year could be observed for e.g. beaches, while mangroves or casuarina forest needed several years to recover. Applying multi-temporal mapping the spatial variations of recovery
\end{abstract}

could be visualised. While some patches of coastal forest were fully recovered after $3 \mathrm{yr}$, other patches were still affected and thus had a reduced capacity to supply ecosystem services. The ecosystem services maps can be used to quantify ecological values and their spatial distribution in the framework of a tsunami risk assessment. Beyond that they are considered to be a useful tool for spatial analysis in coastal risk management in Phang Nga.

\section{Introduction}

\subsection{Ecological impacts of the Indian Ocean tsunami in Phang Nga}

The 2004 Indian Ocean tsunami left a path of destruction along the Andaman Sea coast of Thailand. The coastal areas of Phang Nga province suffered from an extraordinary high number of fatalities, structural damages and economic losses that affected or destroyed the livelihoods of coastal communities (United Nations and Worldbank, 2005). Although fatalities and damages to buildings and infrastructure were the most striking consequences of this tsunami disaster, environmental impacts and damages to ecosystems and related land use/land cover (LULC) also occurred. These included 
uprooted coastal forests, beach erosion, impacts on coral reefs and sea-grass, pollution, contamination from tsunami deposits, and salt infiltration in ground- and surface water as well as in soils affecting vegetation and soil fertility (Choowong et al., 2009; DMCR, 2005a, b; Massmann, 2010; Paphavasit et al., 2009; Pongpiachan et al., 2013; Roemer et al., 2010; Szczucinski et al., 2006; UNEP, 2005; Vosberg, 2010). While the impacts on coral reefs and sea grass beds in the region were comparably small, the damages to coastal forests, e.g. mangroves, and plantations varied spatially, with more severe destruction close to the shore (FAO and MOAC, 2005; Römer, 2011).

Since the interconnection between coastal ecosystem degradation and communities' vulnerabilities has been widely recognized (Adger et al., 2005; Kallesøe et al., 2008; IUCN and UNEP, 2006), negative consequences were supposed to arise from the tsunami impacts due to the dependency of the coastal communities in Phang Nga on the local ecosystems. The economic, social and ecological linkages in the region are manifold, comprising fishing (e.g. shell fish, crab fish, oyster), aquaculture, agriculture, and tourism (Haitook et al., 2011; Willroth et al., 2011). It is therefore important to assess and quantify the ecological values and damages together with the socio-economic ones to evaluate the overall tsunami impact in the framework of a tsunami risk assessment and management.

A way to account for values of ecosystems is the consideration of the functions and services they provide as benefits to humans (MA, 2005; Daily, 1997; Costanza et al., 1997). The concept of ecosystem services (de Groot et al., 2010; Burkhard et al., 2012b) offers a methodological framework for the identification, quantification, evaluation and mapping of land use change on human societies (Burkhard et al., 2012a). It has evolved to a common framework in interdisciplinary ecological and socio-economic research and has high potential to be implemented in management and planning (Burkhard et al., 2012a; Kienast et al., 2009; MA, 2005; Müller and Burkhard, 2007). Ecosystem services also play an important role in risk mitigation of natural hazards and post disaster recovery. Costanza and Farley (2007) emphasised that part of the reason for the severe impacts of coastal disasters is the disregard of ecosystem services in coastal planning. Ecosystems with their functions and services are indeed supposed to reduce disaster impacts by providing natural capital that is essential for the preservation of livelihoods (IUCN and UNEP, 2006).

\subsection{Mapping of ecosystem services}

A common way to assess ecosystem services is the economic valuation (Costanza et al., 1997; MA, 2005; Bateman et al., 2010; Kumar, 2010). Beyond that the spatial analysis of ecosystem service values (Troy and Wilson, 2006) or the analysis of temporal dynamics of ecosystems services (Kroll et al., 2012) is used. Especially the assignment of ecosystem service supply capacities to spatially explicit biophysical units in maps provides useful aggregated information on current supply conditions and changes over space and time (Haines-Young et al., 2012; Burkhard et al., 2012a; Kienast et al., 2009). Spatio-temporal changes can be induced by human LULC changes, climatic change, or disturbances due to natural disasters. These visualisations of ecosystem services and their dynamics are useful tools for decision makers and environmental managers (Swetnam et al., 2011). However, before ecosystem services maps finally can be used for environmental risk management and related spatial planning, the methods need to be developed further and respective data and information have to be acquired in further studies (Daily and Matson, 2008; Burkhard et al., 2012a).

In this case study, we map ecosystem services in connection with impacts of the 2004 Indian Ocean tsunami in Phang Nga, Thailand. The aim is to identify tsunamiinduced LULC changes and to assess and evaluate related alterations in ecosystem service supply capacities. The work has been conducted in the framework of the research project "Tsunami Risks, Vulnerability and Resilience in the Phang Nga and Phuket Provinces, Thailand - Tsunami Risk And Information Tool (TRAIT)" and results will be integrated in an impact and vulnerability assessment for the region.

An approach is applied that indicates different LULC classes' capacities to supply ecosystem services on a relative scale, integrating local expert assessments (based on Burkhard et al., 2009, 2012a; MA, 2005; de Groot, 1992; Costanza, 1997). A similar approach was used by Maes et al. (2011) to map ecosystem services on a European scale, by Nedkov and Burkhard (2012) to map flood regulating ecosystem services in Bulgaria, by Kroll et al. (2012) in a central German peri-urban region, and by Vihervaara et al. (2010) studying the linkages between land use changes and ecosystem services in Lapland, Northern Finland. The approach is considered suitable here since people at the Phang Nga coast benefit from ecosystem services provided by the coastal areas, e.g. for eco-tourism, diving tourism, local farming, and fishery (IUCN and UNEP, 2006; Römer, 2011). Hence, socio-ecological aspects play a major role in the region's vulnerability and coping capacity.

The case study refers to changes in ecological integrity, provisioning, regulating and cultural ecosystem services on a local scale at three different points in time. Altogether, 17 ecosystem services of 18 LULC classes were assessed for pre-tsunami conditions and tsunami induced LULC change and related changes in ecosystem service supply capacities were mapped based on stakeholder interviews, field investigations, remote-sensing and GIS techniques in order to answer the following research questions: 
- Does a combination of land cover data, stakeholder knowledge, field investigations, remote sensing, and GIS enable complex spatial assessments of multiple ecosystem services?

- Can the methods and the resulting maps be used for the evaluation of ecological impacts in the framework of a tsunami risk assessment?

- Can the methods and the resulting maps contribute to coastal risk management?

The paper is structured as follows: in Sect. 2 the study area is introduced. Section 3 describes the methodological approach comprising the development of an ecosystem services matrix, remote-sensing based damage and recovery assessment of LULC, and the development of multi-temporal ecosystem services maps. The resulting matrix and maps are presented in Sect. 4, followed by a discussion in Sect. 5 and conclusions in Sect. 6.

\section{Study area}

The study area covers a $50 \mathrm{~km}$ long, flat coastal stripe from Thai Mueang in the South to Ban Nam Khem in the North in the Phang Nga province, Thailand (Fig. 1). The whole area was devastated by the 2004 tsunami. Settlement structures and ecological characteristics in the area are diverse. Ban Nam Khem is a small community dominated by fishery and agriculture. Further south, Khao Lak has increasingly developed quality tourism structures including eco-tourism and is positioned in the global tourism market (Willroth et al., 2011). The Khao Lampi - Hat Thai Mueang National Park north of Thai Mueang city is located on a spit with a tidal inlet surrounded by mangrove belts, and populated by indigenous people. In all parts of the study area people live in close relation with their environment in terms of agriculture, fishery, or tourism. Dominating LULCs are casuarina forest, mixed beach forest, melaleuca forest, coconut plantations, mangroves, and grassland. Casuarina equisetifolia forms $20-50 \mathrm{~m}$ wide mono-specific stands at sandy coasts (Cochard et al., 2008). Mixed beach and melaleuca forests (Melaleuca leucadendron) are located in the Hat Thai Mueang National park in the south. Coconut plantations ( $\mathrm{Co}$ cos nucifera) are spread all over the study area. According to Yanagisawa et al. (2009) dominant mangrove species found in the study area are Rhizophora sp. and Bruguiera sp. Beyond that grassland, open woodland, beaches, ponds, and build up areas are present (cf. Fig. 3, in Sect. 3.1).

The landscape in the study area is strongly shaped by human activities such as tin mining, shrimp aquaculture, and intensive agricultural use, dominated by the cultivation of rubber, oil palm, coconut, and cashew nut. Fishing and agriculture are a major source of income with $45 \%$ of the population of Phang Nga employed in this sector (Willroth et al., 2011).
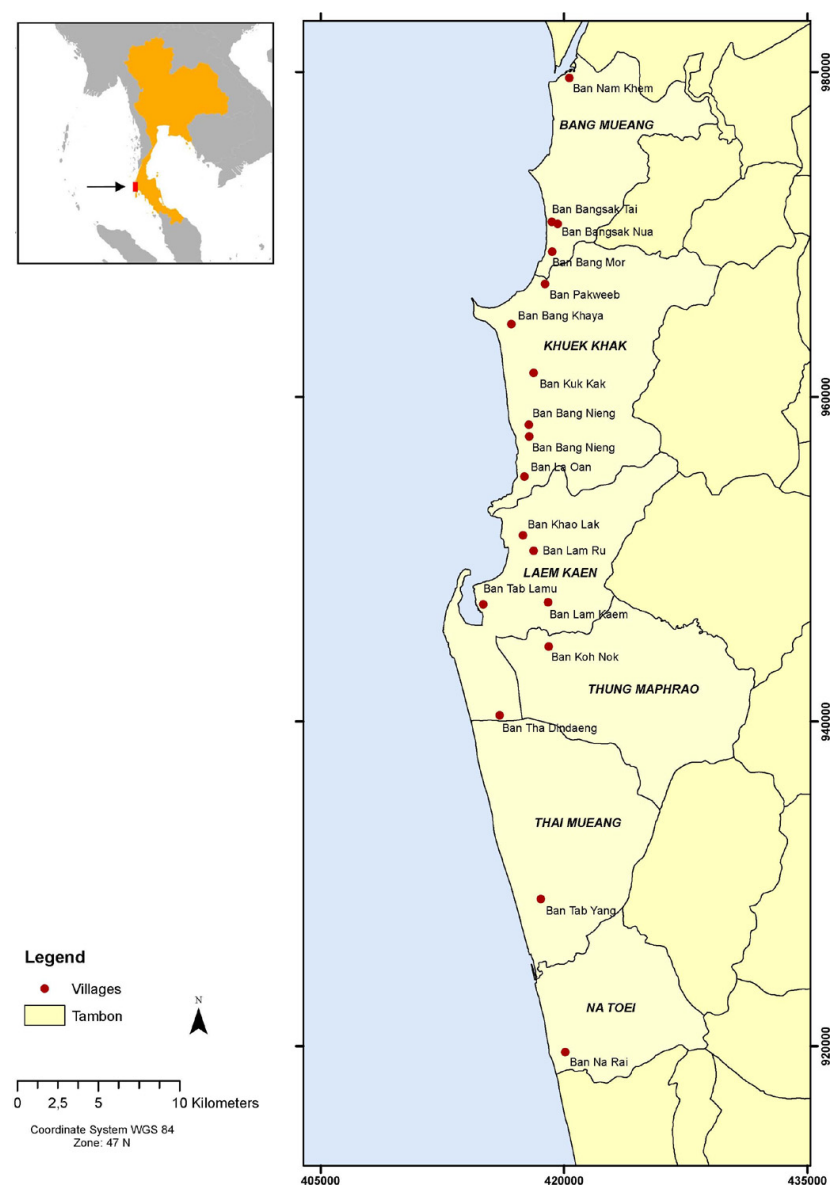

Fig. 1. The study area from Ban Nam Khem in the North, to Thai Mueang, Phang Nga in the South. The 18 villages where interviews took place are included in the map.

Moreover, due to the growing tourism sector, many natural forests have been cleared for development of large hotel complexes. In particular mangroves and coral reefs are under pressure due to marine and coastal development, including for example the expanding shrimp farm industry (Baird et al., 2005; UNEP, 2005; IUCN and UNEP, 2006). The tiger prawn industry, which developed in the 1990s, has led to a dramatic reduction of the mangrove area in South Thailand. By the mid 1990s the initial mangrove area was reduced by about $33 \%$ (FAO and MOAC, 2005).

The 2004 tsunami led to a further impact on coastal ecosystems by destroying large patches of the exposed mangroves, casuarina forests, and coconut plantations and by causing indirect impacts such as defoliation or yellowing of leaves of mixed beach forests and melaleuca forests (Roemer et al., 2010). IUCN and UNEP (2006) estimated the overall economic loss due to damages on coastal ecosystems in the Phang Nga province to about USD 11 million, mainly arising from the destruction of mangroves. 


\section{Methods}

The methodological approach for mapping tsunami impacts on ecosystem service supply includes three steps (Fig. 2):

1. LULC classification based on IKONOS satellite images (2003), and change detection analysis of LULC to detect tsunami damages after the event (2005) as well as recovery processes (2008).

2. Interviews with local stakeholders from coastal villages in Phang Nga as well as Thai governmental and non-governmental organisations to evaluate ecosystem services in the study area using a scoring approach. Development of a matrix for selected ecosystem functions and ecosystem service supply capacities in the study area based on a statistical analysis of the data gained from the interviews.

3. GIS-based mapping of tsunami-induced changes of ecosystem service supply capacities in the different LULC classes.

\subsection{LULC classification, damage and recovery mapping}

The LULC information for the study area was derived from high-resolution satellite images (IKONOS), taken before the tsunami in January 2003, using remote-sensing techniques. For the multi-temporal analysis on damages and recovery IKONOS images from January 2005 and February 2008 were included in the analysis. A rule-based object oriented classification approach was performed for the pre-tsunami image of 2003. The final classification has an overall accuracy of $93.6 \%$ and a Kappa of 0.90, and can therefore be considered as very accurate. The resulting map for the coastal zone between Ban Nam Khem and Thai Mueang city consists of 37 different LULC classes including plantations, beaches, buildings and infrastructure, grassland, water bodies, and natural forests, such as mangroves, casuarina forest, or primary rain forest (Fig. 3). Details of the remote-sensing based LULC classification are provided in Römer (2011).

To derive LULC maps that show the changes that occurred due to the damaging effect of the tsunami, impacts and recovery processes were analysed for selected LULC classes by applying digital change detection techniques based on multitemporal IKONOS imagery (Roemer et al., 2010; Römer et al., 2012b). A damage map (Fig. 4) was generated for January 2005 (post-tsunami) using the direct multi-date classification (DMC) method, which includes a supervised classification of a multi-temporal band composite (Roemer et al., 2010). Damages to LULC classes were categorised in: type $1=$ no damage (no identifiable damage), type $0=$ total damage (e.g. uprooted or removed vegetation), type $0.5=$ indirect damage (degradation of understorey vegetation and soils, applicable to foliage of woody vegetation and to all non-woody vegetation). The damage analysis was conducted

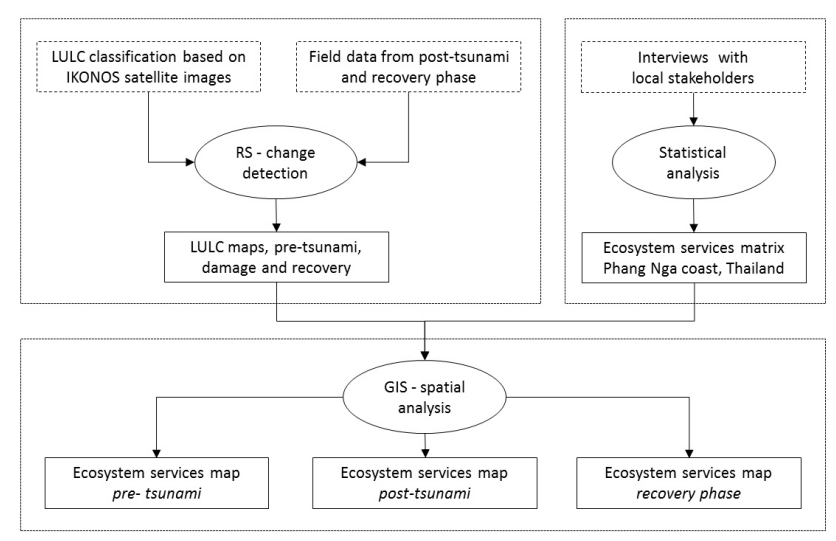

Fig. 2. Methodological approach for mapping changes in ecosystem service supply due to the impact of the 2004 Indian Ocean tsunami.

for the forest ecosystems mangroves, casuarina forest, coconut plantations, mixed beach forest, and melaleuca forest.

For a recovery map $3 \mathrm{yr}$ after the tsunami (2008), the recovery rate was calculated based on multi-temporal Transformed Normalised Vegetation Index (TNDVI) images from three acquisition dates in 2003, 2005 and 2008 (for details see Römer et al., 2012a). The recovery rate was then binary coded in order to distinguish between areas that have recovered or were in a recovery state and those areas indicating persistent situations or even post-tsunami degradation not showing any recovery patterns. Field measurements from 2009 on vegetation recovery and succession were used for validating the change detection results (Römer et al., 2012a). Since the recovery assessment was conducted based on the NDVI, non-vegetated areas were not included in the analysis. The analysis included mangroves, casuarina forest, coconut plantations, and grassland.

Tsunami impacts on the beaches as well as beach recovery were added to the damage and recovery maps by applying a post-classification change detection analysis for beach areas (Vosberg, 2010).

From the LULC classification and the damage and recovery assessment, three maps were generated: (a) a LULC map representing LULC before the tsunami (2003) (Fig. 3), (b) a damage map including a quantification, classification, and spatial distribution of damages to LULC directly after tsunami (2005) (Fig. 4), and (c) a recovery map quantifying and classifying the spatial distribution of recovery from these damages until 2008 (not shown in this paper).

\subsection{Stakeholder interviews and ecosystem services matrix}

On a local scale the value of ecosystems is closely related to the dependencies of coastal communities on ecosystem services for their livelihoods. Therefore, to gain information on the ecosystem services provided and used in the region, interviews with local stakeholders and experts in 


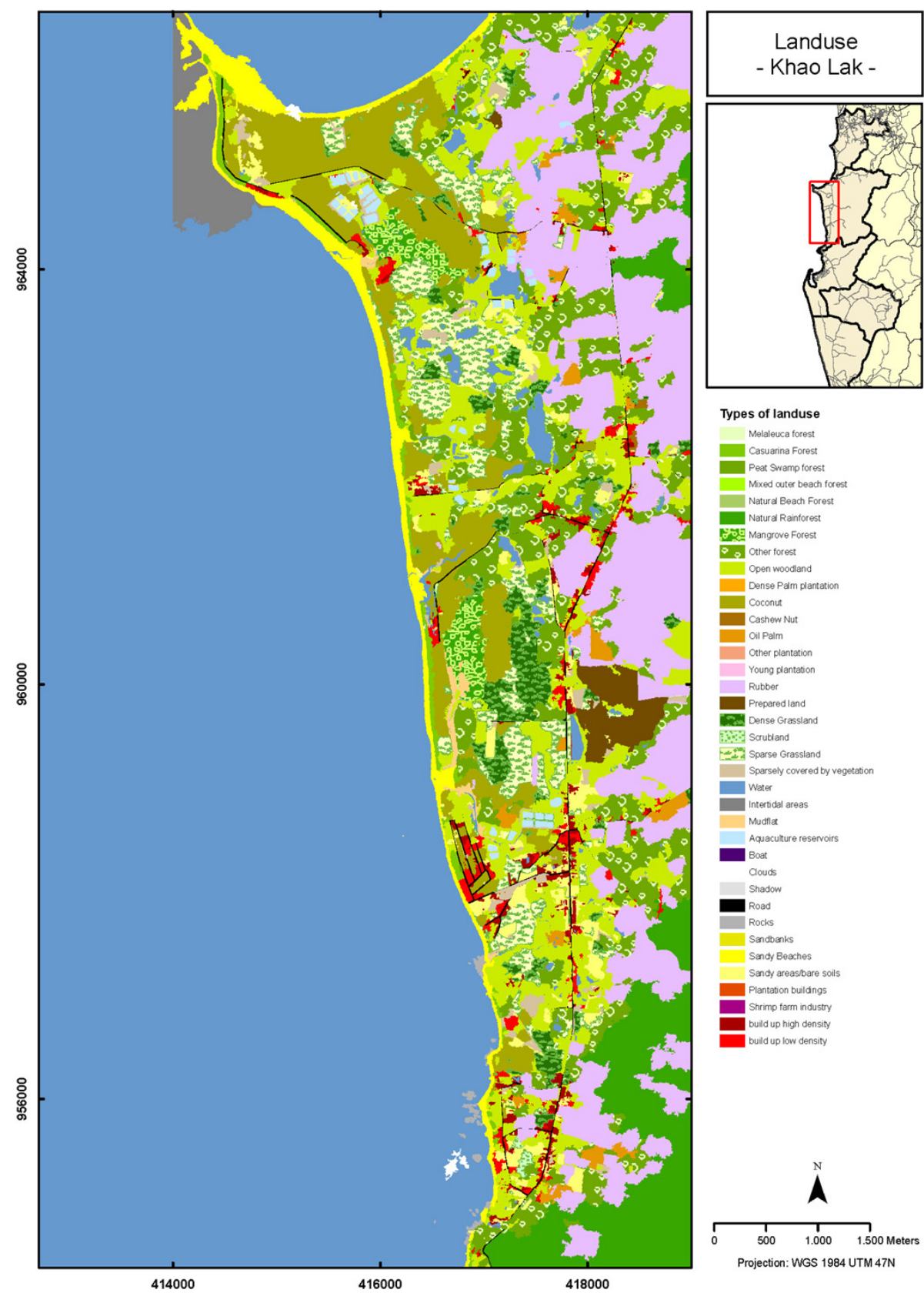

Fig. 3. LULC map exemplified for Khao Lak, based on IKONOS imagery from 13 January 2003.

the field of environmental management were conducted in 18 villages in the districts of Takuapa and Thai Mueang, Phang Nga Province (Fig. 1). Criteria for village selection included (a) a high degree of impact by the 2004 tsunami, and (b) a high degree of diversification of occupation and livelihoods of the people with a close link to coastal and marine resources (Haitook et al., 2011).

A questionnaire was distributed to 33 local stakeholders, whereof 18 persons were village chiefs or village chief assistants from Ban Nam Khem, Khao Lak, and Thai Mueang, nine persons were from governmental organisations and six persons from non-governmental international organizations. The standardised questionnaire included an empty ecosystem services matrix (see Table 2), where scores had to be given for each LULC class and each ecosystem service according to the respondents' local knowledge and experience.

The study covered 17 ecosystem functions and services of 18 LULC classes (Tables 1 and 2). The 18 LULC classes were (partly) merged from the original 37 LULC classes identified by the remote-sensing based classification (Fig. 3). The following ten LULC classes were excluded from the analysis: plantation buildings, shrimp farm industry 


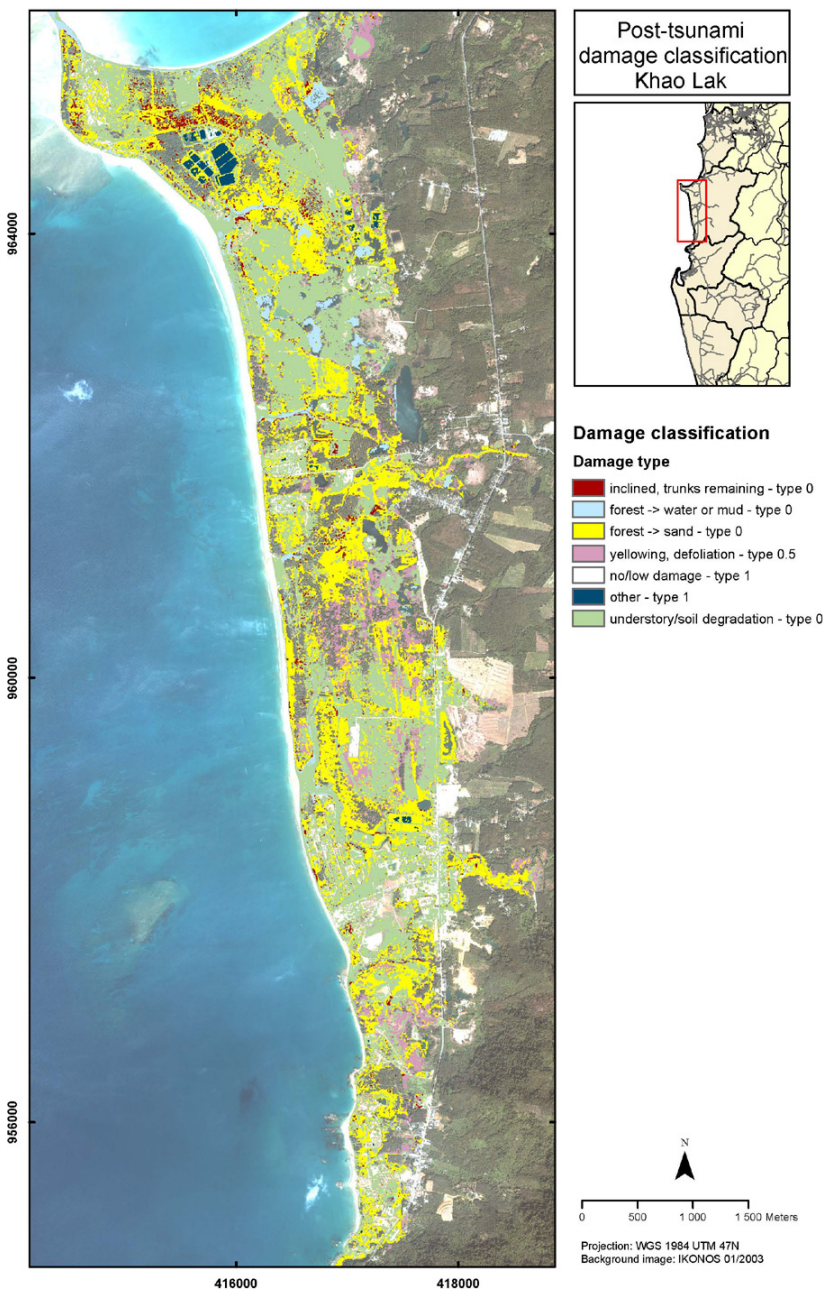

Fig. 4. Tsunami damage map for Khao Lak showing the spatial distribution and the type of damages to vegetation directly after the tsunami in 2005. Beach erosion is not included in the map. Areas with no/low damage are transparent. The method (Direct MultiDate Classification) and data are described in Roemer et al. (2010). For the damage map applied in the ecosystem services maps, damage types have been summarised to type 1 (no damage), type 0 (total damage), and type 0.5 (indirect damage).

buildings, build up areas high density, build up areas low density, prepared land, boats, clouds, shadow, roads, and rocks. Some of the other categories were merged as follows: beach (sandy beaches, sandbanks), tidal inlet (mudflat, intertidal areas), rubber (rubber plantation, younger plantation), coconut plantation (coconut, other plantation), natural grassland (dense grassland, scrubland, sparse grassland, sparsely covered by vegetation, open woodland), oil plantation (dense palm plantation, oil palm), mixed beach forest (rain forest, other forest, mixed outer beach forest, natural beach forest).

The ecosystem functions and services were organised in the four categories: ecological integrity, provisioning services, regulating services, and cultural services (Burkhard et al., 2009, 2012a). Ecological integrity refers to ecosystem structures and processes responsible for ecosystem functioning and self-organisation (Müller, 2005; Müller and Burkhard, 2007; Barkmann et al., 2001). From the eight ecological integrity indicators initially suggested by Müller (2005), the ecosystem structure indicator "biodiversity" and the process indicator "nutrient cycling" were selected to be assessed in this study. The authors are aware that there are manifold categorisations for ecosystem functions and services and the related scientific debate, for example concerning problems of potential double counting, is not finished yet (Wallace, 2007). However, related studies are so singular, question- and context-related, so that perhaps a common classification framework is neither feasible nor really necessary (Burkhard et al., 2012b; Costanza, 2008). In this study, the focus was on illustrating spatial distributions of ecosystem function and service supply and their temporal changes. No "total ecosystem values" have been summed up in the end. Moreover, the two assessed ecological integrity components "biodiversity" and "nutrient cycling" are not considered in any of the other ecosystem service categories here. Therefore, problems of double counting were not involved.

Provisioning services include products that humans can derive from ecosystems, e.g. food or raw materials. Regulating services are ecological regulation mechanisms (such as coastal protection by coastal forests or ground water recharge) that are important for human activities. Cultural services are important for the quality of life and for spiritual inspiration, but also for economic aspects, i.e. tourism. The selection of ecosystem services in the three categories is mainly based on de Groot et al. (2010), Burkhard et al. (2009, 2012a), MA (2005) and suggestions from local stakeholders and experts for site-specific services. For example, the service "provisioning of shade" was highly recognised by the locals for their daily activities. Therefore, it was included in the study as a new and innovative aspect compared to existing ecosystem service categorisations.

In Table 1, an overview on the ecosystem functions and services assessed in this study is given.

The respondents were asked to rate each ecosystem service according to its overall importance in and for the communities in the region.

For the assessment of different LULC classes' capacities to support ecosystem integrity or to supply ecosystem services, the following rating scale was applied (after Burkhard et al., 2009, 2012a): $0=$ no relevant capacity, $1=$ low relevant capacity, $2=$ relevant capacity, $3=$ medium relevant capacity, $4=$ high relevant capacity, and $5=$ very high relevant capacity.

In addition, for a better interpretation of the results, further questions were included in the questionnaire on the respondents' evaluation of tsunami impacts on LULC and ecosystem service supply and their observations regarding the recovery progress in the region. The respondents were asked to categorise the damages to each LULC class according to 
Table 1. Ecosystem functions and services investigated in this study.

\begin{tabular}{|c|c|c|}
\hline & Short description & References \\
\hline \multicolumn{3}{|c|}{ Ecological functions and integrity } \\
\hline Biodiversity & $\begin{array}{l}\text { The presence and absence of selected species, } \\
\text { (functional) groups of species, biotic habitat } \\
\text { components or species composition. }\end{array}$ & $\begin{array}{l}\text { Müller (2005), MA (2005), } \\
\text { Müller and Burkhard (2007), } \\
\text { Burkhard et al. (2009), }\end{array}$ \\
\hline Nutrient cycling & $\begin{array}{l}\text { The capacity of an ecosystem to cycle nutrients } \\
\text { and matter and thereby preventing the irreversible } \\
\text { output of elements from the system. }\end{array}$ & $\begin{array}{l}\text { De Groot (1992), } \\
\text { Forbes and Broadhead (2007), } \\
\text { Kandziora et al. (2013) }\end{array}$ \\
\hline \multicolumn{3}{|l|}{ Provisioning services } \\
\hline Food & $\begin{array}{l}\text { Food obtained from: crops, livestock, captured fisheries, } \\
\text { aquaculture, wild-foods and oil as well as presence of } \\
\text { edible plants and animals. }\end{array}$ & $\begin{array}{l}\text { Burkhard et al. (2009), } \\
\text { de Groot et al. (2010) }\end{array}$ \\
\hline Wood/fibre/oil/timber & $\begin{array}{l}\text { Timber and fibre harvesting, e.g. for ornament making } \\
\text { and tools. Presence of species or abiotic components } \\
\text { with potential use for timber, fuel or raw material. }\end{array}$ & $\begin{array}{l}\text { Burkhard et al. (2009), } \\
\text { de Groot et al. (2010) }\end{array}$ \\
\hline Medicine & $\begin{array}{l}\text { Production of bio-chemicals, medicines and presence of } \\
\text { species or abiotic components with potential chemical } \\
\text { and/or medical use. }\end{array}$ & $\begin{array}{l}\text { Burkhard et al. (2009), } \\
\text { de Groot et al. (2010) }\end{array}$ \\
\hline Energy/biomass & $\begin{array}{l}\text { Presence of trees or plants with potential } \\
\text { use as energy source, e.g. wood fuel cooking. }\end{array}$ & Burkhard et al. (2009) \\
\hline Freshwater supply & $\begin{array}{l}\text { Presence of fresh water from coastal aquifers } \\
\text { or groundwater reservoirs. }\end{array}$ & $\begin{array}{l}\text { Burkhard et al. (2009), } \\
\text { Haitook et al. (2011), } \\
\text { Graterol (2011) }\end{array}$ \\
\hline \multicolumn{3}{|l|}{ Regulating services } \\
\hline Local climate regulation & $\begin{array}{l}\text { Changes in land cover can locally affect temperature, } \\
\text { wind, radiation and precipitation. }\end{array}$ & Burkhard et al. (2009) \\
\hline Coastal protection & $\begin{array}{l}\text { Refers to natural elements that reduce the impact of extreme } \\
\text { flood events, e.g. the role of forests in dampening } \\
\text { wave impact. }\end{array}$ & $\begin{array}{l}\text { Burkhard et al. (2009), } \\
\text { de Groot et al. (2010) }\end{array}$ \\
\hline Erosion regulation & $\begin{array}{l}\text { In this study referring to the vegetation cover } \\
\text { at the coast and the patches of sea-grass offshore } \\
\text { that prevent beach erosion. }\end{array}$ & $\begin{array}{l}\text { Haitook et al. (2011), } \\
\text { Graterol (2011) }\end{array}$ \\
\hline Water purification & Refers to the general capacity of ecosystems to purify fresh water. & Burkhard et al. (2009) \\
\hline Provisioning of shade & $\begin{array}{l}\text { Presence of trees along the streets and beaches and } \\
\text { along the coastline that people use to protect } \\
\text { themselves from the intense solar radiation. }\end{array}$ & $\begin{array}{l}\text { Haitook et al. (2011), } \\
\text { Graterol (2011), } \\
\text { de Groot (1992) }\end{array}$ \\
\hline Pollination & $\begin{array}{l}\text { Ecosystem changes affect the distribution, abundance, } \\
\text { and effectiveness of pollinators. Wind and bees are in charge of } \\
\text { the reproduction of a lot of plants of cultural importance. }\end{array}$ & $\begin{array}{l}\text { Burkhard et al. (2009), } \\
\text { de Groot et al. (2010) }\end{array}$ \\
\hline Ground water recharge & $\begin{array}{l}\text { Changes in land cover strongly influence the timing and } \\
\text { magnitude of runoff, flooding, and aquifer recharge. }\end{array}$ & Burkhard et al. (2009) \\
\hline \multicolumn{3}{|l|}{ Cultural services } \\
\hline Aesthetic value & $\begin{array}{l}\text { Refers to the visual qualities of the area (beauty of the place). } \\
\text { Aesthetic information has considerable influence on the quality of life. }\end{array}$ & de Groot (1992) \\
\hline Recreation and tourism & $\begin{array}{l}\text { Refers to the recreational activities that people can enjoy in the area } \\
\text { (fun activities for relaxation, e.g. nature walks, hiking, snorkelling, } \\
\text { guided tours, elephant rides) and available facilities } \\
\text { (e.g. hotels, parks, restaurants, stores, swimming pools). }\end{array}$ & de Groot et al. (2010) \\
\hline Education/research & $\begin{array}{l}\text { Features with special educational and scientific value/interest, } \\
\text { i.e. referring to the extent to which the area attract scientist } \\
\text { to study certain phenomena and to the opportunities } \\
\text { that area offers to teach about the natural system. }\end{array}$ & de Groot et al. (2010) \\
\hline
\end{tabular}


their local knowledge in "no/minor damage", "polluted/salt intrusion", and "destroyed/washed away/broken". Moreover they were asked to estimate the duration of the recovery process (Table 4). In addition, group discussions were conducted in some villages with about four to eight persons in each group to discuss these questions (Haitook et al., 2011).

When analysing the results it should be taken into account that the scoring was often difficult for the respondents and answers can be very subjective depending on peoples' personal experience (Fagerholm et al., 2012),

A descriptive statistical analysis was conducted to analyse the data from the scoring of the local stakeholders. For all LULC classes and all services, the scores were analysed using the statistical median. It has to be mentioned here, that not all 33 respondents ranked all services for all LULC classes. Very few answers were given for melaleuca forest (9), aquaculture (7), and natural grassland (2).

\subsection{Creation of ecosystem services maps}

To create the maps with the spatial distribution of ecosystem service supply capacities (pre-tsunami ecosystem services maps), the matrix (Table 2) was linked to the pre-tsunami LULC map in GIS by assigning the ecosystem service supply capacity scores to each polygon (biophysical unit) in the LULC map (after Burkhard et al., 2009, 2012a).

The post-tsunami ecosystem services maps were derived by combining the pre-tsunami ecosystem services maps with the damage classification, which was derived from the change detection analysis (Sect. 3.1). The percentage of the damage in each LULC polygon was multiplied by the pre-tsunami ecosystem service supply capacity score. The ecosystem service supply capacity score of the damaged part was then subtracted from the original score in order to get the ecosystem service supply capacity score, which was left after the tsunami (Eq. 1, Fig. 5).

$\mathrm{ESSC}_{\text {post }}=\mathrm{ESSC}_{\mathrm{s}} \cdot(1-d)$

where $\mathrm{ESSC}_{\text {post }}=$ Ecosystem service supply capacity score post tsunami, $\mathrm{ESSC}_{\mathrm{s}}=\mathrm{ESSC}$ score, $d=$ damage in 2005.

Recovery refers to the potential and the rate at which vegetation reclaims its habitat by natural succession processes after being degraded or removed by the tsunami in 2004 (Römer et al., 2012a). To derive the ecosystem service supply capacity scores during recovery in 2008 , the recovery was multiplied by the damages and the pre-tsunami ecosystem service supply capacity score, and added to each ecosystem service's post-tsunami ESSC score. This operation provided the respective ecosystem service supply capacity scores for 2008 (Eq. 2, Fig. 5).

$\mathrm{ESSC}_{\mathrm{rec}}=r^{*} d^{*} \mathrm{ESSC}_{\mathrm{s}}+\mathrm{ESSC}_{\mathrm{post}}$

where $\mathrm{ESSC}_{\mathrm{rec}}=$ Ecosystem service supply capacity score after recovery, $r=$ recovery in 2008, $d=$ damage in 2005, $\mathrm{ESSC}_{\text {post }}=\mathrm{ESSC}$ score post tsunami.

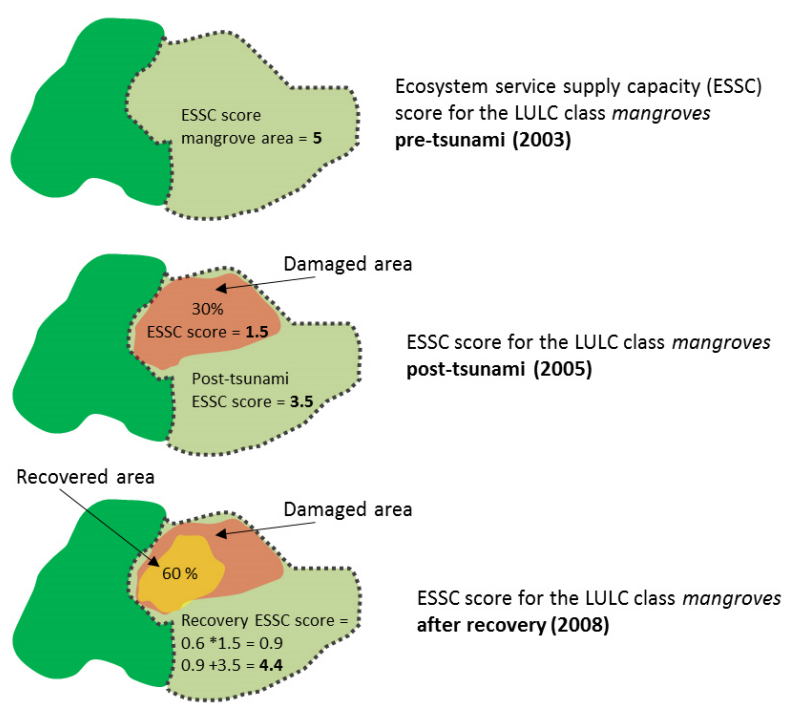

Fig. 5. Sketch describing the approach to calculate the ecosystem service supply capacity scores for the post-tsunami and the recovery phase (cf. Eqs. 1 and 2).

\section{Results}

\subsection{Ecosystem services matrix}

Results show, that the Phang Nga coast has a high capacity to support ecosystem functions and to supply services from a variety of LULC classes (Table 2). These can be considered of great importance for the livelihood of the local people and also for tourism and the economy of the region.

The ecosystem services matrix (Table 2), derived from the statistical analysis of the local stakeholder scoring shows that, according to the respondents' perception, mangroves, casuarina forest, mixed beach forest, coral reefs, tidal inlets, and wetlands (here peat swamp forest) provide the highest overall ecosystem service supply capacity. Lowest scores were given to plantations and aquaculture. In general the function "biodiversity" as well the services "food provisioning", "coastal protection" and all cultural services are considered to be particularly important in the region. This reflects the character of the study area, which is dominated by tourism and related activities, small business of local people at the beach, as well as fishery and agriculture.

Mangroves, which are known to be among the most valuable coastal ecosystems in the world (ten Brink, 2011), are also considered to be particularly important in almost all services. For mangroves the ecosystem functions "biodiversity" and "nutrient cycling" have been ranked with the highest score of 5. Mangroves are also considered to provide regulating services, such as "climate regulation" or "coastal protection" (also ranked with 5) by stabilising sediment and partly attenuating wave energy. Moreover, mangroves are an important food source as well as of cultural value for locals and 
Table 2. Ecosystem services matrix for the coastal areas of the Phang Nga province, Thailand linking LULC classes to their capacities to support ecosystem functions and to supply ecosystem services on the scale: $0=$ no relevant capacity, $1=$ low relevant capacity, $2=$ relevant capacity, 3 = medium relevant capacity, 4 = high relevant capacity, $5=$ very high relevant capacity.

$\mathrm{n}$ : Mangroves $=24$, Casuarina forest $=21$, Rubber plantation $=20$, Coconut plantation $=23$, Orchard $/$ Cashew nut $=12$, Oil palm plantation $=20$, Mixed beach forest $=21$, Melaleuca forest $=9$, Beach $=23$, Tidal Inlet $=26$, Coral reefs $=21$, Sea grass $=19$, Aquaculture $=7$, Natural grassland $=2$, Wetlands $=12$, Ocean $=21$, Pond $=20$, Stream $/$ river $/$ channel $=17$.

\begin{tabular}{|c|c|c|c|c|c|c|c|c|c|c|c|c|c|c|c|c|c|c|c|c|c|c|}
\hline Code & LULC class & 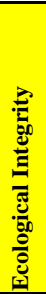 & 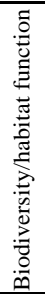 & 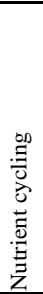 & 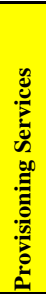 & 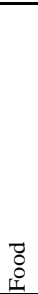 & 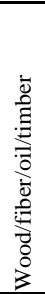 & 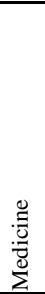 & 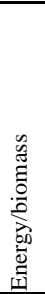 & 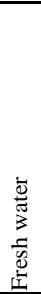 & 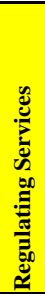 & 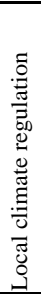 & 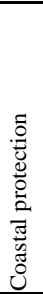 & 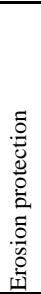 & 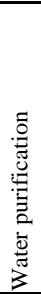 & 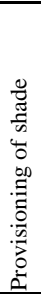 & 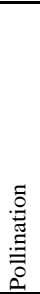 & 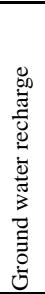 & 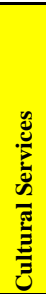 & 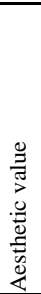 & 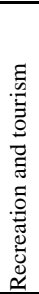 & 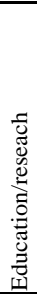 \\
\hline 1 & Mangroves & & 5 & 5 & & $\overline{5}$ & 4 & 3 & 2 & 0 & & 5 & 5 & 5 & 4 & 4 & 4 & 4 & & 4 & 4 & $\overline{5}$ \\
\hline 2 & Casuarina forest & & 3 & 4 & & 2 & 3 & 0 & 2 & 0 & & 4 & 5 & 4 & 3 & 4 & 4 & 4 & & 4 & 5 & 4 \\
\hline 3 & Rubber plantation & & 1 & 4 & & 0 & 5 & 0 & 2 & 0 & & 4 & 0 & 2 & 2 & 4 & 2 & 3 & & 3 & 3 & 3 \\
\hline 4 & Coconut plantation & & 2 & 3 & & 4 & 3 & 2 & 1 & 0 & & 3 & 3 & 3 & 3 & 3 & 3 & 3 & & 4 & 3 & 2 \\
\hline 5 & Orchard/Cashew nut & & 1 & 3 & & 3 & 0 & 0 & 0 & 0 & & 3 & 0 & 2 & 2 & 3 & 3 & 2 & & 3 & 2 & 2 \\
\hline 6 & Oil palm plantation & & 2 & 2 & & 1 & 0 & 0 & 0 & 0 & & 3 & 0 & 3 & 3 & 4 & 2 & 3 & & 4 & 3 & 3 \\
\hline 7 & Mixed beach forest & & 4 & 4 & & 4 & 3 & 2 & 2 & 0 & & 5 & 5 & 5 & 4 & 4 & 4 & 4 & & 5 & 5 & 4 \\
\hline 8 & Melaleuca forest & & 3 & 4 & & 3 & 3 & 1 & 1 & 0 & & 4 & 3 & 4 & 3 & 3 & 3 & 4 & & 4 & 3 & 3 \\
\hline 9 & Beach & & 3 & 3 & & 3 & 0 & 0 & 0 & 0 & & 3 & 3 & 4 & 4 & 0 & 3 & 3 & & 5 & 5 & 4 \\
\hline 10 & Tidal inlet & & 5 & 4 & & 5 & 0 & 0 & 0 & 4 & & 4 & 4 & 3 & 3 & 2 & 4 & 3 & & 4 & 4 & 3 \\
\hline 11 & Coral reefs & & 5 & 4 & & 5 & 0 & 0 & 0 & 0 & & 4 & 3 & 4 & 4 & 1 & 5 & 3 & & 5 & 5 & 5 \\
\hline 12 & Sea grass & & 5 & 4 & & 5 & 0 & 1 & 0 & 0 & & 4 & 3 & 4 & 3 & 1 & 4 & 3 & & 4 & 3 & 4 \\
\hline 13 & Aquaculture & & 2 & 3 & & 4 & 0 & 0 & 0 & 0 & & 3 & 2 & 1 & 1 & 1 & 0 & 3 & & 2 & 2 & 3 \\
\hline 14 & Natural grassland & & 3 & 4 & & 4 & 0 & 0 & 0 & 0 & & 4 & 4 & 4 & 4 & 1 & 4 & 4 & & 4 & 4 & 4 \\
\hline 15 & Wetlands & & 4 & 5 & & 4 & 2 & 2 & 1 & 3 & & 4 & 3 & 3 & 4 & 3 & 3 & 4 & & 4 & 3 & 4 \\
\hline 16 & Ocean & & 5 & 5 & & 5 & 0 & 0 & 0 & 5 & & 5 & 0 & 0 & 2 & 0 & 3 & 0 & & 4 & 5 & 3 \\
\hline 17 & Pond & & 4 & 3 & & 3 & 0 & 0 & 0 & 4 & & 4 & 0 & 0 & 3 & 0 & 4 & 3 & & 4 & 3 & 2 \\
\hline 18 & Stream/river/channel & & 4 & 4 & & 3 & 0 & 0 & 0 & 4 & & 4 & 0 & 2 & 3 & 0 & 4 & 3 & & 4 & 4 & 3 \\
\hline
\end{tabular}

\begin{tabular}{|cl|}
\hline Assessment scale \\
\hline 0 & No relevant capacity \\
1 & Low relevant capacity \\
2 & Relevant capacity \\
3 & Medium relevant capacity \\
4 & High relevant capacity \\
5 & Very high relevant capacity \\
\hline
\end{tabular}

tourists in the area. The other coastal forests, i.e. casuarina forest or mixed beach forest, are considered to have a high ecosystem service supply capacity, especially in the regulating and cultural services.

According to the respondents, also local peat swamp forest (wetlands) is important for the supply of regulating services, such as "climate regulation", "water purification", or "ground water recharge".

Plantations are widely distributed in the study area. They are not natural forests and are considered to have only low and medium relevant capacities in most of the services. They are an important food source, though, and therefore play a major role for agriculture in the study area. Moreover, plantations are considered to provide cultural services as they contribute to the tropical scenery.

Grassland (open woodland, scrubland, dense and sparse grassland) makes up a large part of the study area. It was ranked high by the respondents in regulating and cultural services as well as ecological integrity. Grassland is considered to protect from erosion and flooding, but also to contribute to the aesthetic value of the region.

Coral reefs, the ocean, long tropical beaches, and water courses are important for recreation and tourism in the study area. Seaside tourism contributes significantly to the development and the income of the region (Willroth et al., 2011). Moreover, local people use the beach for their daily small business, e.g. selling of fruits or for relaxing from the heat in the shade of trees. Besides the cultural services coral reefs are considered to provide important regulating services.

Coastal aquacultures are increasing in the area and are therefore included in this study. They provide mainly food and are considered to have a function for education and research. 
Table 3. Damage and recovery rates of coastal forests in the study area (derived from remote sensing techniques).

\begin{tabular}{|c|c|c|c|c|c|c|}
\hline \multirow[t]{2}{*}{ Ecosystem } & \multirow[t]{2}{*}{ Total area 2003 (ha) } & \multicolumn{2}{|c|}{ Direct tsunami impacts } & \multicolumn{3}{|c|}{ Recovery processes } \\
\hline & & area (ha) & $\%$ of exposed area & area (ha) & $\%$ of impacted area ${ }^{a}$ & recovery rate ${ }^{b}$ \\
\hline Mangroves & 980.17 & 59.59 & 6.15 & 33.49 & 54.10 & Slow \\
\hline Casuarina & 98.06 & 37.24 & 37.98 & 20.78 & 61.60 & Fast \\
\hline Coconut plantation & 494 & 124.61 & 25.22 & 97.32 & 78.10 & None \\
\hline Melaleuca forest & 49.13 & 0.56 & 1.14 & $\mathrm{n} / \mathrm{a}$ & $\mathrm{n} / \mathrm{a}$ & Fast \\
\hline Mixed beach forest & 193.05 & 1.72 & 0.89 & $\mathrm{n} / \mathrm{a}$ & $\mathrm{n} / \mathrm{a}$ & Fast \\
\hline
\end{tabular}

a Derived from TNDVI-approach (Römer et al., 2012a). ${ }^{\mathrm{b}}$ Estimated from field observations conducted in 2009.

\subsection{Pre-, post tsunami and recovery ecosystem services maps}

Damage and recovery rates for coastal forests in the study area from the change detection analysis (Sect. 3.1) are shown in Table 3 (for details see Roemer et al., 2010; Römer et al., 2012b). Casuarina forests suffered the greatest damage with $38 \%$ of trees destroyed in the inundated coastal zone. Also $25 \%$ of all coconut plantations in the exposed area and about $6 \%$ of the mangroves, but only small patches of melaleuca and mixed beach forest were destroyed. There has been a rapid recovery of casuarina forest and more than $60 \%$ had recovered by 2008. Plantations are not natural ecosystems, so that recovery is related to undergrowth recovery or the plantation of new trees. A natural recovery of plantation patches would lead to a growth of casuarinas.

Based on the ecosystem services matrix (Table 2), the damage analysis, and the recovery analysis, pre-, posttsunami, and recovery maps were produced using the method described in Sect. 3.3. The maps show the spatial distribution of ecosystem service supply capacities before the tsunami, as well as spatio-temporal changes of the supply capacities due to the tsunami impact.

Maps for the services "coastal protection" and "food provisioning" for Kao Lak are shown in Figs. 6 and 7.

The post-tsunami maps show that almost all biophysical units located in the inundated area were affected by a loss of ecosystem service supply capacities. Since the study area was flooded up to $1 \mathrm{~km}$ inland (Römer et al., 2012b), vast patches of coastal forest have been washed away or damaged, beaches were eroded and there was intrusion of salt water into the ground. With the loss of vegetation and soil, the services provided by the affected LULC were reduced.

Among the exposed forest ecosystems in the study area, mangroves and casuarina forest were mostly affected by the tsunami. When washed away, their coastal and erosion protection service was lost after the event. Moreover their capacity to provide food and other goods was disrupted. Also large patches of grassland lost some of their services due to damage to vegetation and salt water intrusion. The recovery maps show a recovery in all biophysical units in 2008. However, recovery rates vary spatially. In some areas in Khao
Lak mangroves showed almost no recovery until 2008, while other patches completely recovered. Results also suggest that rubber and coconut plantations had a faster recovery or reafforestation rate than mangroves and casuarina forest. The results gained from the multi-temporal satellite analysis and ecosystem services mapping match with the results from the interviews conducted with local experts on damages and recovery processes in the region (Haitook et al., 2011, Table 4).

Comparing the pre-/post-/ and recovery maps for the service "coastal protection" (Fig. 6) shows high to very high supply capacities in the pre-tsunami state, where coastal forests are located. Casuarina forests are located parallel to the coast, building a natural green belt that shields the hinterland from impacts from the sea. Two mangrove patches, located in tidal inlets are also supposed to serve as protection.

The post-tsunami map shows that all biophysical units in the inundated area suffered from a decrease or loss of the coastal protection service. The overall reduction of the coastal protection service is mainly due to the damage of coastal forests.

The recovery map indicates that large parts of the study area recovered to some extent until 2008. However, the coastal protection service of the casuarina forest and the northern mangrove patch is still significantly reduced, while the southern patch is fully recovered. Beaches have recovered in almost all parts of the area, but are still smaller in more exposed areas in the North. Moreover tidal inlets were not fully recovered in 2008 (Vosberg, 2010). Therefore, also for beaches the coastal protection service supply capacity in 2008 varies locally.

Many LULC classes in the study area supply food (Fig. 7). Coconut plantations and mangroves have shown to have a very high relevant capacity for food provisioning, but also tidal areas and coral reefs are important food sources, e.g. fish. The post-tsunami map reveals that the service supply capacity for the provisioning of food has been strongly reduced, mainly due to the damage to agricultural areas (e.g. plantations). Some of the plantations have been completely reforested by 2008 , but many still have a reduced service supply capacity. The spatial variations can be seen in Fig. 7. 

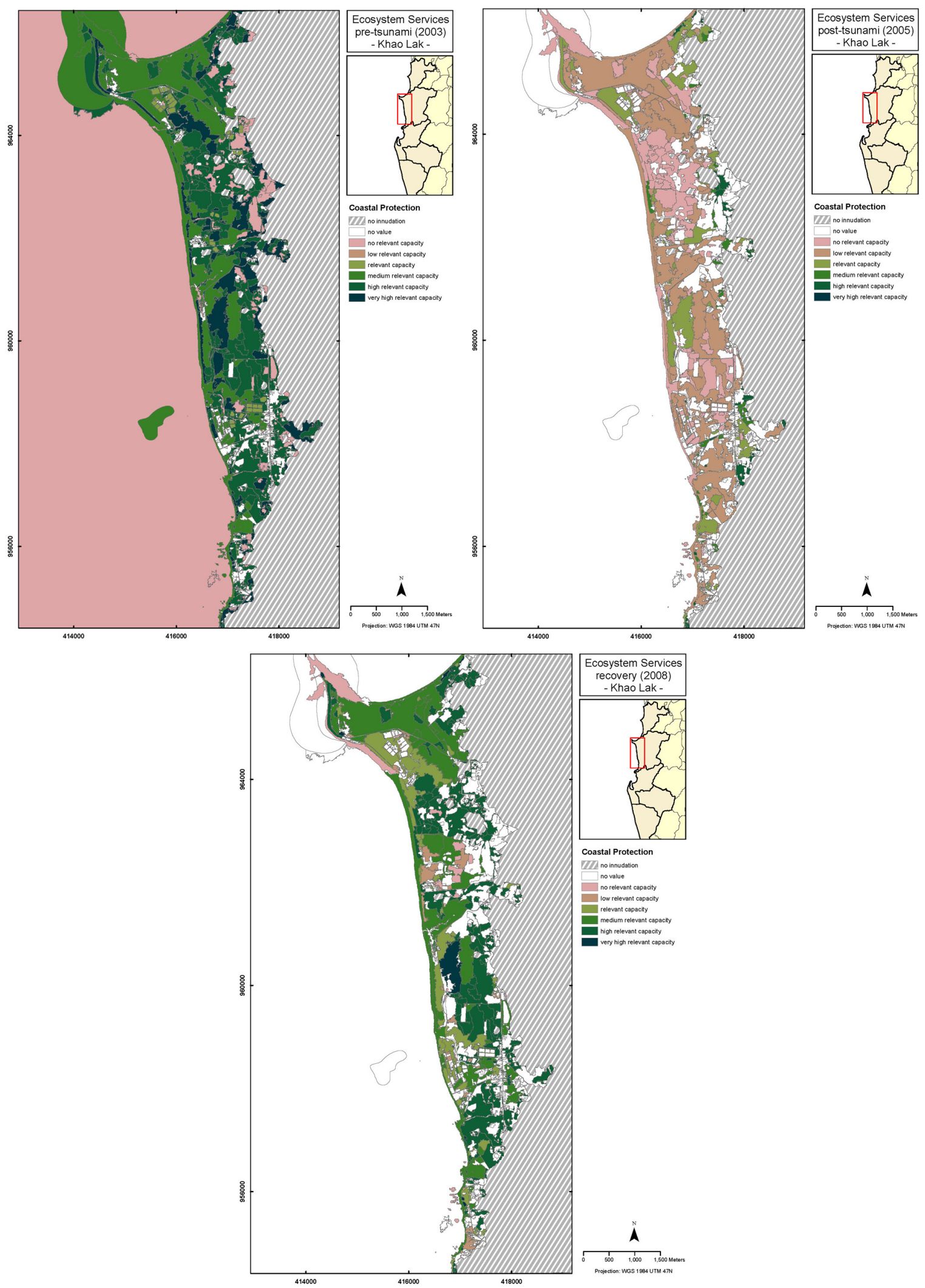

Fig. 6. Map showing the spatial distribution of the ecosystem service "coastal protection" for Khao Lak before the tsunami 2003 (upper panel, left), after the tsunami (01/2005, upper panel, right), and after a recovery time (02/2008, lower panel). White areas represent areas not included in the analysis or no data available on damages or recovery of LULC classes (e.g. ocean, coral reefs, and sea-grass, rubber). 

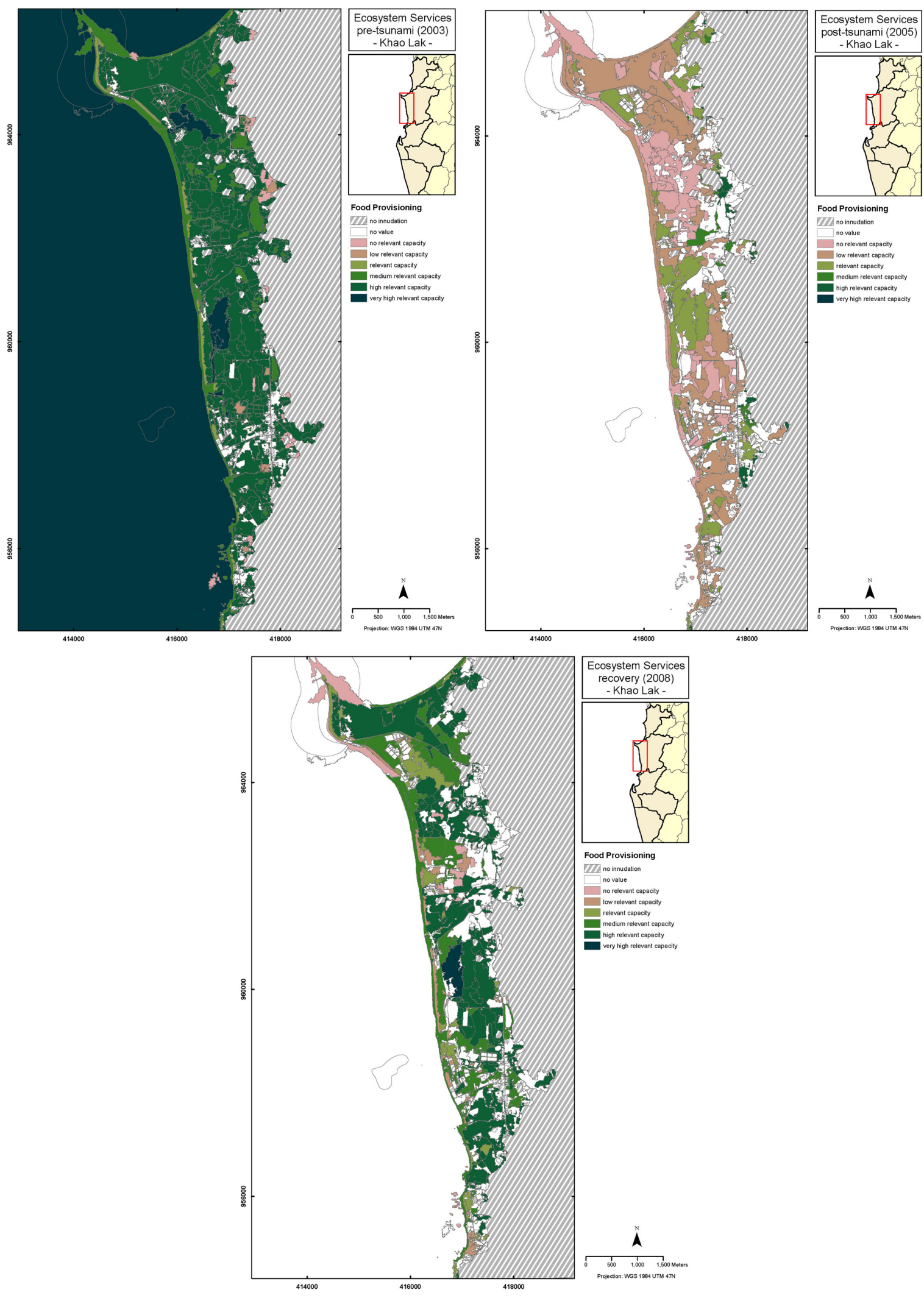

Fig. 7. Map showing the spatial distribution of the ecosystem service "food provisioning" before the tsunami 2003 (upper panel, left), after the tsunami (01/2005, upper panel, right) and after a recovery time (02/2008, lower panel). White areas represent areas not included in the analysis or no data available on damages or recovery of LULC classes (e.g. ocean, coral reefs, and sea-grass, rubber). 
Table 4. Damage and recovery of ecosystem service supply capacities due to the tsunami. The values of the ecosystem services by LULC class are derived from the matrix in Table 2. Type of damage and recovery and duration of service reduction were derived from stakeholder interviews using the statistical median for all answers (modified from Haitook et al., 2011).

\begin{tabular}{llllc}
\hline $\begin{array}{l}\text { LULC } \\
\text { class }\end{array}$ & $\begin{array}{l}\text { Value of ecosystem services } \\
\text { based on the matrix in Table 2 }\end{array}$ & $\begin{array}{l}\text { Type of damage } \\
\text { to the ecosystem }\end{array}$ & $\begin{array}{l}\text { Duration of service } \\
\text { reduction due } \\
\text { to the tsunami }\end{array}$ & $\begin{array}{c}\text { Ecosystem service supply } \\
\text { capacity in 2010 (\% of } \\
\text { pre-tsunami conditions) }\end{array}$ \\
\hline Mangroves & High relevant capacity & Destroyed/washed away/broken & $1-5 \mathrm{yr}$ & 75.83 \\
Casuarina forest & High relevant capacity & Destroyed/washed away/broken & $1-5 \mathrm{yr}$ & 85.24 \\
Rubber plantation & Relevant capacity & No/minor damage & No influence & 99.00 \\
Coconut plantation & Medium relevant capacity & Pollution/salt intrusion & 2 weeks-1 yr & 89.13 \\
Orchard/Cashew nut & Relevant capacity & Pollution/salt intrusion & 2 weeks-1 yr & 82.50 \\
Oil palm plantation & Relevant capacity & No/minor damage & No influence & 99.00 \\
Mixed beach forest & High relevant capacity & Destroyed/washed away/broken & $1-5 \mathrm{yr}$ & 77.62 \\
Melaleuca forest & Medium relevant capacity & Pollution/salt intrusion & 2 weeks-1 yr & 95.56 \\
Beach & Medium relevant capacity & Pollution/salt intrusion/erosion & 2 weeks-1 yr & 93.04 \\
Tidal inlet & High relevant capacity & Pollution/salt intrusion/erosion & 2 weeks-1 yr & 88.46 \\
Coral reefs & High relevant capacity & Destroyed/washed away/broken & $1-5 \mathrm{yr}$ & 66.19 \\
Sea-grass & Medium relevant capacity & Damage & $1-5 \mathrm{yr}$ & 65.26 \\
Aquaculture & Relevant capacity & Destroyed/washed away/broken & 2 weeks-1 yr & $1-5 \mathrm{yr}$ \\
Natural grassland & High relevant capacity & Pollution/salt intrusion & $1-14$ \\
Wetlands & Medium relevant capacity & Pollution/salt intrusion & No influence & 100.00 \\
Ocean & Medium relevant capacity & Pollution & 2 weeks-1 yr & 97.50 \\
Pond & Medium relevant capacity & Pollution/salt intrusion & $1-5 \mathrm{yr}$ & 100.00 \\
Stream/river/channel & Medium relevant capacity & Pollution/salt intrusion & 2 weeks-1 yr & 90.50 \\
\hline
\end{tabular}

Similar maps can be produced for all ecosystem services. With these maps spatial variations in changes of ecosystem service supply capacities for single biophysical units can be visualised and monitored. The additional questions in the questionnaire revealed that, according to the local respondents' experience, among the forest ecosystems, mangroves, casuarina forest and mixed beach forest had the longest period (1-5 yr) of reduction of ecosystem service supply capacities after the tsunami (Table 4). Also coral reefs and seagrass beds are considered to have a long recovery period. In contrast, a shorter recovery period of less than two weeks to maximum one year has been observed for salt water intrusion or pollution in coconut and cashew nut plantations, or melaleuca forest.

At the time of the survey in 2010 , more than $5 \mathrm{yr}$ after the tsunami, the respondents stated that most of the ecosystems were able to supply $80 \%$ of their pre-tsunami services. They describe remaining ecosystem service supply capacity deficits for mangroves, mixed beach forest, coral reefs and sea grass.

\section{Discussion}

In this study, we used detailed high resolution spatial data and conducted stakeholder interviews to acquire very accurate spatio-temporal landscape patterns. Based on these data tsunami impacts on ecosystem service supply at the Phang Nga coast could be mapped.
Our results show, that the methodology of combining remote sensing techniques, field investigations, stakeholder interviews and GIS was a useful tool to (a) quantify the damages to ecosystems and related LULC in a spatially explicit way, (b) provide ecosystem service supply capacity scores for single LULC classes, and (c) visualise changes of ecosystem service supply capacities (losses as well as recovery processes). This yields a specific analysis of the local situation, the benefits local communities obtain from their environment as well as the losses of these benefits due to a tsunami impact.

GIS and remote-sensing based data and maps showing the spatial distribution of ecosystem services can be used in land-use planning and management (Troy and Wilson, 2006; Grêt-Regamey et al., 2008). The ecosystem services maps derived in this study can in addition be integrated in tsunami risk assessment and mapping since they can be used to quantify ecological values and their spatial distribution in the framework of an exposure analysis. In this way the maps can be combined with other spatial data such as maps with the distribution of economic values in a flood prone area. Moreover, the post tsunami mapping approach suggested in this study allows the quantification of damages to LULC by means of loss of ecosystem service supply capacities and related socio-economic consequences. Since the maps provide information for every biophysical unit, dynamics in LULC change and related potential losses of ecosystem service supply can be monitored for larger areas applying multi-temporal image analyses. This makes the maps also useful tools for tsunami risk management and coastal planning, for example by showing the correlation between 
bio-shields and settlement structures, or by demonstrating the potential losses of services from mangroves when aquaculture or hotel complexes are planned to substitute them. This phenomenon has also been addressed by Tallis and Polasky (2009) who stated that decision-makers might overlook the variety of ecosystem services, when developing management plans. The interviews with the local stakeholders and discussions with the local people in our study area revealed that people do not use mangroves for wood as much as before the tsunami due to laws and management regulations as well as the increased awareness of the bio-shield function of mangroves and other coastal forests (Haitook et al., 2011). The maps produced in this study could contribute to this kind of management regulations.

Another example where the maps could be used is related to the growth of the shrimp farm industry and of tourism in Phang Nga which implicates direct short-term economic profit for the region, but does not consider the value losses by clearing coastal forests, which might cause negative economic consequences in the long-term perspective, for example, reduced flood protection or loss of food sources.

During this work some limitations of the methodology became obvious. The matrix is subjective which cannot be avoided because the interviews reflect the respondents experience, knowledge and attitude. Some services might have been underestimated because the scores assigned by the survey's participants indicate the services they know and use, but these scores do not necessarily consider the full potential of the ecosystems to supply their services, as proposed in the literature. This makes the matrix somewhat vulnerable to misinformation and misinterpretation (Burkhard et al., 2009; Hou et al., 2013). However, when comparing the scoring of the local stakeholders with a comprehensive literature review in Graterol (2011), a general good agreement could be observed for most of the LULC classes and their service supply capacities with other studies. Nevertheless there were some discrepancies. The local stakeholders ranked the coastal protection service of coastal forests, especially mangroves, very high (score $=5$ ) in the study area. This was also confirmed by local experience during the 2004 tsunami (Haitook et al., 2011). However, on the other hand, there is an ongoing controversial discussion on the protective role of coastal forests against tsunami waves (Cochard et al., 2008). Although experiments and field investigations proved that there is a potential to reduce wave energy and flow velocities, it is still not clear to what degree and if this actually prevents severe damages (Dahdouh-Guebas et al., 2005; Danielsen et al., 2005; Das and Vincent, 2009; Kathiresan and Rajendran, 2005; Kerr et al., 2006; Strusińska-Correia et al., 2013; Tanaka, 2009).

The local respondents gave very low scores for the services "medicine", "energy/biomass" and "fresh water supply" for almost all LULC classes. This is assumed to be either due to a lack of knowledge or because people do not use these services in the region. However, casuarina forest, coral reefs or sea grass, for example, are actually known to provide substances that can be used for medical purpose (Ali et al., 2012; Birkeland, 1997; Whistler and Elevitch, 2006). Also the service "energy" provided for example by rivers was not mentioned here, most likely because rivers in the region are not used to gain hydropower. The provisioning of wood and other goods was perhaps underestimated by the locals since, according to their statements in the group discussions they do not cut trees to derive wood for construction and therefore do not consider the service important. They also do not use corals as market goods. "Pollination" was assessed very high from the locals also in water bodies, from coral reefs and sea-grass. However, pollination does not occur in water bodies or is known to be negligible (see also Costanza et al., 1997). Therefore, we assume a misunderstanding in the interviews here. Despite this mismatch with literature in some points, we find the locals' perspective relevant for a local assessment of tsunami impacts as perceived by those people who experienced the 2004 tsunami disaster and its consequences, e.g. in terms of loss of ecosystem services, for their personal livelihood.

Burkhard et al. (2009) emphasised that one weakness of this approach is, that it has so far been overlooking important aspects such as scale-dependencies (temporal and spatial), scale-interactions, and habitat heterogeneities. The method of calculating ecosystem service scores in the post tsunami and recovery maps, is based on the assumption that the loss and the recovery of ecosystem service supply capacities is directly related to the amount of damage of the biophysical units, i.e. a forest patch destroyed by $50 \%$ of its area has also a reduction of its ecosystem service supply capacity by $50 \%$. This assumption neglects the complexity of the biophysical processes and spatial gradients and is only true for some of the services.

Like in all integrative interdisciplinary landscape assessments, uncertainties originate due to human-environmental system complexity as well as data and methodological uncertainties (Hou et al., 2013). For the interviews, more specific questions could be asked in order to effectively produce evaluations that are, for example, comparable from one ecosystem service to another. On the other hand, when carrying out interviews on such rather complex issues with the target to address all most relevant ecosystem functions, services and their linkages to land cover types, we argue that several generalisations and lack of some detail need to be accepted in order to gain thematic diversity. The use of additional spatial information such as maps or satellite images presented to the interview respondents could have been used in order to facilitate the assessments or to calibrate the results afterwards. Fagerholm et al. (2012) proved that stakeholders are able to identify and map different landscape-related values, perceptions and services.

Moreover, the use of binary damage and recovery maps to classify damages and recovery of LULC is a rather simple approach which does not include all processes of change. 
Damage and recovery was indirectly estimated based on the spatial changes in LULC. These changes describe only the loss or increase of biomass but they do not indicate the quality of these changes (species composition, nutrient cycling, etc.). A more detailed damage analysis can be performed using sophisticated remote-sensing techniques, which allow a very accurate damage and recovery classification for small areas (as described in Roemer et al., 2010).

Despite this simplification the advantage of the approach is its applicability and transferability to other areas and other natural hazards as well as its potential to integrate additional data as soon as they are available. Moreover, it provides a spatial distribution of changes in ecosystems service supply capacities even for larger areas.

\section{Conclusions}

The paper presents a case study and a methodological approach to track LULC changes and to map related alterations in ecosystem service supply capacities due to an extreme event. The study revealed that, when sufficient data on LULC changes are available, the approach of combining a multi-temporal analysis of LULC changes, with an ecosystem services matrix facilitates a visualisation of the spatial distribution of ecosystem service supply capacities in maps, yielding valuable information on the consequences of the 2004 tsunami. Results have shown that coastal ecosystems in Phang Nga are vulnerable to LULC change (natural or anthropogenic) threatening the supply of multiple lifesustaining ecosystem services. Stakeholder interviews conducted to evaluate ecosystem service supply capacities provided useful insights in the locals' perception of natural goods and their use and therefore reflect on actual losses people in the region obtained from tsunami-induced damages to coastal ecosystems.

However, some limitations and uncertainties of the methodology have to be taken into account. Especially correlating the size of a damaged LULC patch with the loss of ecosystem service supply capacities needs further improvement.

It is believed here that the approach to quantitatively evaluate tsunami impacts on ecosystems with the loss of their capacity to supply services, a mapping of their spatial distribution, as well as monitoring recovery are useful tools for tsunami risk assessment and long-term coastal risk management, delivering reasonable outcomes with acceptable time and labour efforts.

Acknowledgements. The work presented in this paper was conducted in the project "Tsunami Risks, Vulnerability and Resilience in the Phang Nga Province, Thailand (TRAIT)" which was funded by the German Research Foundation (DFG) in the framework of the bilateral German-Thai research cooperation TRIAS. The authors would like to thank Christopher Dunbar and colleagues from WWF Thailand for their support in extensive field surveys and for giving us insights into the socio-ecological structures in the region, all the local stakeholders, NGOs and institutions involved in the interviews and group discussions for their support and contributions, as well as Birger Dircks and Johannes Tiffert for the GIS support. We gratefully acknowledge the support given by the Norwegian Geotechnical Institute (NGI) for the writing of this paper. Finally, we would like to thank the anonymous referees for their helpful comments to improve the paper.

Edited by: K. Schwarzer

Reviewed by: four anonymous referees

\section{References}

Adger, W. N., Hughes, T., Folke, C., Carpenter, S., and Rockström, J.: Socio-ecological resilience to coastal disasters, Science, 309, 5737, doi:10.1126/science.1112122, 2005.

Ali, M. S., Ravikumar, S., and Beula, J. M.: Bioactivity of seagrass against the dengue fever mosquito Aedes aegypti larvae, Asian Pac. J. Trop. Biomed., 2, 570-573, doi:10.1016/S22211691(12)60099-9, 2012.

Baird, A. H., Campbell, S. J., Anggoro, A. W., Ardiwijaya, R. L., Fadli, N., Herdiana, Y., Kartawijaya, T., Mahyiddin, D., Mukminin, A., Pardede, S. T., Pratchett, M. S., Rudi, E., and Siregar, A. M.: Acehnese Reefs in the Wake of the Asian Tsunami, Curr. Biol., 15, 1926-1930, doi:10.1016/j.cub.2005.09.036, 2005.

Barkmann, J., Baumann, R., Meyer, U., Müller, F., and Windhorst, W.: Ökologische Integrität: Risikovorsorge im nachhaltigen Landschaftsmanagement, GAIA, 10, 97-108, 2001 (in German).

Bateman, I. J., Mace, G. M., Fezzi, C., Atkinson, G., and Turner, R. K.: Economic analysis for ecosystem service assessments, Environ. Resour. Econ., 48, 177-218, doi:10.1007/s10640-010-9418$\mathrm{x}, 2010$.

Birkeland, C.: Life and Death of Coral reefs, Chapman and Hall, New York, 536 pp., 1997.

Burkhard, B., Kroll, F., Müller, F., and Windhorst, W.: Landscapes' Capacities to Provide Ecosystem Services - a Concept for LandCover Based Assessments, Landscape Online, 15, 1-22, 2009.

Burkhard, B., Kroll, F., Nedkov, S., and Müller, F.: Mapping supply, demand and budgets of ecosystem services, Ecol. Indic., 21, 1729, doi:10.1016/j.ecolind.2011.06.019, 2012a.

Burkhard, B., de Groot, R. S., Costanza, R., Seppelt, R., Jørgensen, S. E., and Potschin, M.: Solutions for Sustaining Natural Capital and Ecosystem Services, Ecol. Indic., 21, 1-6, doi:10.1016/j.ecolind.2012.03.008, 2012b.

Choowong, M., Phantuwongraj, S., Charoentitirat, T., Chutakosikanon, V., Yumuang, S., and Charusiri, P.: Beach recovery after 2004 Indian Ocean tsunami from Phang Nga, Thailand, Geomorphology, 104, 134-142, 2009.

Cochard, R., Ranamukhaarachchi, S. L., Shivakoti, G. P., Shipin, O. V., Edwards, P. J., and Seeland, K. T.: The 2004 tsunami in Aceh and Southern Thailand: A review on coastal ecosystems, wave hazards and vulnerability, Perspect. Plant. Ecol., 10, 3-40, 2008.

Costanza, R.: Ecosystem services: Multiple classification systems are needed, Biol. Conserv., 141, 350-352, 2008. 
Costanza, R. and Farley, J.: Ecological economics of coastal disasters: Introduction to the special issue, Ecol. Econ., 63, 249-253, 2007.

Costanza, R., d'Arge, R., de Groot, R., Farber, S., Grasso, M., Hannon, B., Limburg, K., Naeem, S., O’Neill, R. V., Paruelo, J., Raskin, R. G., Sutton, P., and van den Belt, M.: The value of the world's ecosystem services and natural capital, Nature, 387, 253-260, 1997.

Dahdouh-Guebas, F., Jayatissa, L. P., Di Nitto, D., Bosire, J. O., Lo Seen, D., and Koedam, N.: How effective were mangroves as a defence against the recent tsunami, Curr. Biol., 15, 443-447, 2005.

Daily, G. C.: Nature's services: societal dependence on natural ecosystems, Island Press, Washington DC, 392 pp., 1997.

Daily, G. C. and Matson, P. A.: Ecosystem Services: From theory to implementation, P. Natl. Acad. Sci. USA, 105, 9455-9456, 2008.

Danielsen, F., Sørensen, M. K., Olwig, M. F., Selvam, V., Parish, F., Burgess, N. D., Hiraishi, T., Karunagaran, V. M., Rasmussen, M. S., Hansen, L. B., Quarto, A., and Suryadiputra, N.: The Asian tsunami: a protective role for coastal vegetation, Science, 310 , 5748, p. 643, 2005.

Das, S. and Vincent, J. R.: Mangroves protected villages and reduced death toll during Indian super cyclone, P. Natl. Acad. Sci. USA, 106, 7357-7360, doi:10.1073/pnas.0810440106, 2009.

De Groot, R. S.: Functions of Nature: Evaluation of nature in environmental planning, management and decision-making, Wolters, Nordhoff BV, Groningen, The Netherlands, 1992.

De Groot, R. S., Alkemade, R., Braat, L., Hein, L., and Willemen, L.: Challenges in integrating the concept of ecosystem services and values in landscape planning, management and decision making, Ecol. Complexity, 7, 260-272, 2010.

DMCR (Department of Marine and Coastal Resources and Thammasat University): Post tsunami impact on mangrove community and status quo of surrounding community: The case study in the area of Mangrove Resource Development Center, Phang Nga, Department of Marine and Coastal Resources, Ministry of natural Resources and Environment, Bangkok, Thailand, 100 pp., 2005a.

DMCR (Department of Marine and Coastal Resources): Rapid Assessment of the Tsunami Impact on Marine Resources in the Andaman Sea, Thailand, Phuket Marine Biological Center (PMBC), Phuket, Thailand, 76 pp., 2005 b.

Fagerholm, N., Käyhkö, N., Ndumbaro, F., and Khamis, M.: Community stakeholders' knowledge in landscape assessments Mapping indicators for landscape services, Ecol. Indic., 18, 421433, 2012.

FAO and MOAC (Food and Agriculture Organisation of the United Nations and Ministry of Agriculture \& Cooperation): Report of Joint FAO/MOAC Detailed Technical Damages and Needs Assessment Mission in Fisheries and Agriculture Sectors in Tsunami Affected Six Provinces in Thailand, 11-14 January 2005, available at: http://www.apfic.org/apfic_downloads/ tsunami/FAO_MOAC_thai.pdf, last access: 12 August 2010, 2005.

Forbes, K. and Broadhead, J.: The role of coastal forests in the mitigation of tsunami impacts, FAO, Food and Agriculture Organization of the United Nations, Regional Office for Asia and the Pacific, Bangkok, 30 pp., 2007.
Graterol, R. M.: The utility of the ecosystem services approach in disaster risk reduction: a case study in the Phang Nga province, Thailand, MSc thesis, University of Kiel, Germany, 2011.

Grêt-Regamey, A., Bebi, P., Bishop, I. D., and Schmid, W. A.: Linking GIS-based models to value ecosystem services in an Alpine region, J. Environ. Manage., 89, 197-208, 2008.

Haines-Young, R., Potschin, M., and Kienast, F.: Indicators of ecosystem service potential at European scales: mapping marginal changes and trade-offs, Ecol. Indic., 21, 39-53, 2012.

Haitook, T., Sangkaew, S., and Dunbar, C.: Post-tsunami recovery assessment, Phang Nga Province, Thailand, unpublished TRAIT project report, 2011.

Hou, Y., Burkhard, B., and Müller, F.: Uncertainties in landscape analysis and ecosystem service assessment, J. Environ. Manage., 127, S117-S131, doi:10.1016/j.jenvman.2012.12.002, 2013.

IUCN and UNEP: Counting the Environmental Costs of Natural Disasters: Evaluating Tsunami-Related Damages to Coastal Ecosystems in Thailand. Ecosystems and Livelihoods Group Asia, Colombo, Sri Lanka, 36 pp., 2006.

Kallesøe, M. F., Bambaradeniya, C. N. B., Iftikhar, U. A., Ranasinghe, T., and Miththapala, S.: Linking Coastal Ecosystems and Human Well-Being: Learning from conceptual frameworks and empirical results, Colombo: Ecosystems and Livelihoods Group, Asia, IUCN, viii + 49 pp., 2008.

Kandziora, M., Burkhard, B., and Müller, F.: Interactions of ecosystem properties, ecosystem integrity and ecosystem service indicators - A theoretical matrix exercise, Ecol. Indic., 28, 54-78, 2013.

Kathiresan, K. and Rajendram, N.: Coastal mangrove forests mitigated tsunami, Estuar. Coast. Shelf S., 65, 601-606, 2005.

Kerr, A. M., Baird, A. H., and Campbell, S. J.: Comments on "Coastal mangrove forests mitigated tsunami" by K. Kathiresan and N. Rajendran [Estuar. Coast. Shelf S., 65, 601e606, 2005], Estuar. Coast. Shelf S., 67, 539-541, 2006.

Kienast, F., Bolliger, J., Potschin, M., de Groot, R. S., Verburg, P. H., Heller, I., Wascher, D., and Haines-Young, R.: Assessing Landscape Functions with Broad-Scale Environmental Data: Insights Gained from a Prototype Development for Europe, Environ. Manage., 44, 1099-1120, 2009.

Kroll, F., Müller, F., Haase, D., and Fohrer, N.: Rural-urban gradient analysis of ecosystem services supply and demand dynamics, Land Use Policy, 29, 521-535, 2012.

Kumar, P.: The Economics of Ecosystems and Biodiversity - Ecological and Economic Foundations, Earthscan, London, Washington, 2010.

MA (Millennium Ecosystem Assessment): Ecosystems and Human Well-being: Synthesis, Island Press, Washington, DC, World Resources Institute, 2005.

Maes, J., Paracchini, M. L., and Zulian, G.: A European assessment of the provision of ecosystem services: Towards an atlas of ecosystem services, Luxembourg: Publications Office of the European Union, 81 pp., doi:10.2788/63557, 2011.

Massmann, F.: Analyse der Vulnerabilität von Landwirtschaft und Fischerei an der Andamanküste Thailands im Kontext des Tsunamis von 2004, Diploma thesis, Institute of Geography, Christian-Albrechts-Universität Kiel, Germany, 2010 (in German).

Müller F.: Indicating ecosystem and landscape organisation, Ecol. Indic., 5, 280-294, 2005. 
Müller, F. and Burkhard, B.: An ecosystem based framework to link landscape structures, functions and services, in: Multifunctional Land Use - Meeting Future Demands for Landscape Goods and Services, edited by: Mander, Ü., Wiggering, H., and Helming, K., Springer Berlin Heidelberg, 37-64, 2007.

Nedkov, S. and Burkhard, B.: Flood Regulating Ecosystem Services - Mapping Supply and Demand in the Etropole Municipality, Bulgaria, Ecol. Indic., 21, 67-79, doi:10.1016/j.ecolind.2011.06.022, 2012.

Paphavasit, N., Aksornkoae, S., and De Silvia, J.: Tsunami Impact on Mangrove Ecosystem, Thailand Environmental Institute, Nonthaburi, Thailand, 211 pp., 2009.

Pongpiachan, S., Tipmanee, D., Deelaman, W., Muprasit, J., Feldens, P., and Schwarzer, K.: Risk assessment of the presence of polycyclic aromatic hydrocarbons (PAHs) in coastal areas of Thailand affected by the 2004 tsunami, Mar. Pollut. Bull., doi:10.1016/j.marpolbul.2013.07.052, 2013.

Roemer, H., Kaiser, G., Sterr, H., and Ludwig, R.: Using remote sensing to assess tsunami-induced impacts on coastal forest ecosystems at the Andaman Sea coast of Thailand, Nat. Hazards Earth Syst. Sci., 10, 729-745, doi:10.5194/nhess-10-729-2010, 2010.

Römer, H.: Assessment of tsunami vulnerability and resilience of coastal ecosystems at the Andaman Sea coast of Thailand - potential and limitations of remote sensing and GIS techniques for a local scale approach, Ph.D. thesis, Christian-AlbrechtsUniversität zu Kiel, Germany, 186 pp., 2011.

Römer, H., Jeewarongkakul, J., Kaiser, G., Ludwig, R., and Sterr, H.: Monitoring post tsunami vegetation recovery in Phang Nga, Thailand - a remote sensing based approach, Int. J. Remote Sens., 33, 3090-3121, doi:10.1080/01431161.2011.628710, 2012a.

Römer, H., Willroth, P., Kaiser, G., Vafeidis, A. T., Ludwig, R., Sterr, H., and Revilla Diez, J.: Potential of remote sensing techniques for tsunami hazard and vulnerability analysis - a case study from Phang-Nga province, Thailand, Nat. Hazards Earth Syst. Sci., 12, 2103-2126, doi:10.5194/nhess-12-21032012, 2012b.

Swetnam, R. D., Fisher, B., Mbilinyi, B. P., Munishi, P. K. T., Willcock, S., Ricketts, T., Mwakalila, S., Balmford, A., Burgess, N. D., Marshall, A. R., and Lewis, S. L.: Mapping socio-economic scenarios of land cover change: A GIS method to enable ecosystem service modelling, J. Environ. Manage., 92, 563-574, 2011.

Strusińska-Correia, A., Husrin, S., and Oumeraci, H.: Tsunami damping by mangrove forest: a laboratory study using parameterized trees, Nat. Hazards Earth Syst. Sci., 13, 483-503, doi:10.5194/nhess-13-483-2013, 2013.
Szczucinski, W., Chaimanee, N., Niedzielski, P., Rachlewicz, G., Saisuttichai, D., Tepsuwan, T., Lorenc, S., and Siepak, J.: Environmental and Geological Impacts of the 26 December 2004 Tsunami in Coastal Zone of Thailand - Overview of Short and Long-Term Effects, Pol. J. Environ. Stud., 793-810, 2006.

Tallis, H. and Polasky. S.: Mapping and Valuing Ecosystem Services as an Approach for Conservation and Natural-Resource Management, Ann. NY Acad. Sci., 1162, 265-283, 2009.

Tanaka, N.: Vegetation bioshields for tsunami mitigation: review of effectiveness, limitations, construction, and sustainable management, Landsc. Ecol. Eng., 5, 71-79, 2009.

ten Brink, P.: The Economics of Ecosystems and Biodiversity in International and National Policy Making. An Output of TEEB: The Economics of Ecosystems and Biodiversity, Earthscan, London, Washington DC, 2011.

Troy, A. and Wilson, M. A.: Mapping ecosystem services: Practical challenges and opportunities in linking GIS and value transfer, Ecol. Econ., 60, 435-449, 2006.

UNEP (United Nations Environment Programme): After the Tsunami, Rapid Environmental Assessment, Nairobi, Kenia, 140 pp., 2005.

United Nations and Worldbank: Tsunami Thailand. One year later, United Nations Country Team, Bangkok, 2005.

Vihervaara, P., Kumpula, T., Tanskanen, A., and Burkhard, B.: Ecosystem services - A tool for sustainable management of human-environment systems, Case study Finnish Forest Lapland, Ecol. Complex., 8, 410-420, 2010.

Vosberg, Z.: Veränderung der Strandmorphologie an der thailändischen Andamankueste nach dem Tsunami 2004, BSc thesis, Institute of Geography, Christian-Albrechts-Universität Kiel, Germany, 2010 (in German).

Wallace, K.: Classification of ecosystem services: problems and solutions, Biol. Conserv., 139, 235-246, 2007.

Whistler, W. A. and Elevitch, C. R.: Casuarina equisetifolia (beach she-oak) C. cunninghamiana (river she-oak), Species Profiles for Pacific Island Agroforestry, The Traditional Tree Initiative, Hawaii, USA, available at: http://traditionaltree.org, last access: 7 October 2010, 2006.

Willroth, P., Revilla Diez, J., and Arunotai, N.: Modelling the economic vulnerability of households in the Phang Nga Province (Thailand) to natural disasters, Nat. Hazards, 58, 753-769, doi:10.1007/s11069-010-9635-1, 2011

Yanagisawa, H., Koshimura, S., Goto, K., Miyagi, T., Imamura, F., Ruangrassamee, A., and Tanavud, C.: The reduction effects of mangrove forest on a tsunami based on field surveys at Pakarang Cape, Thailand and numerical analysis, Estuar. Coast. Shelf S., 81, 27-37, 2009. 